\title{
METHODOLOGICAL APPROACHES TO MODELING INFORMATION ARCHITECTURE OF THE ORGANIZATION IN THE CONDITIONS OF DIGITAL ECONOMY
}

\author{
Pavlo Hrynko \\ Department of International Economics ${ }^{1}$ \\ pavelgrinko@gmail.com \\ Alla Grinko \\ Department of Management ${ }^{1}$ \\ grinko.alla@gmail.com \\ ${ }^{1}$ Kharkiv State University of Food Technology and Trade \\ 333 Klochkivska str., Kharkiv, Ukraine, 61051
}

\begin{abstract}
It is significant for businesses, especially in the digital economy, the solution of theoretical and methodological justifications and the development of practical recommendations for building an organization's information architecture as a holistic description of its key strategies, related to business, information, application systems and technologies, and also their impact on the functions and business processes of an organization.

The article discusses issues, related to methodological approaches to modeling an organization's information architectureб using information management tools to help manage innovation in information systems (IS) and information technologies (IT). The relevance of organizational provisions to determine the way, in which a business entity's business model is functionally integrated with the IS architecture is substantiated. The consideration and analysis of the use of industrial standards for describing the architecture of an organization, adopted by such institutions as the International Organization for Standardization (ISO), The Open Group, Institute of Electrical and Electronics Engineers (IEEE), etc. reveal that none of these standards is dominant and does not provide teams, responsible for the architecture development with all the tools, necessary from the methodological point of view and from the point of view of the templates, used to describe the architecture. Recommendations are given on the theoretical and methodological substantiation and construction of the information architecture of an organization as a complete description of its key strategies related to business, information, application systems and technologies, as well as their impact on the functions and business processes of an organization.
\end{abstract}

Keywords: business architecture of an organization, IT architecture, business management model, information management.

DOI: $10.21303 / 2504-5571.2020 .001137$

\section{Introduction}

The processes of globalization and integration are related to finding organizations ways to increase their performance. The same processes are forcing them to use an information technology more widely to support management. Already, the use of virtual networks is leading to a rapid change in the methods of trade in goods and services, management methods, ways of creating jobs. It is currently difficult to gauge the full progress of these technologies. Existing and emerging information technologies are being developed, so managers and contractors must understand the basic concepts and uses of information technology and be able to make important decisions about their use. The responsibility of a manager in the field of such technologies is to possess the technique of personal work in the information environment and the ability to make the right strategic decisions, regarding the development of information systems of organizations. Entrepreneurs need to be able to manage information and improve their business by using it properly to increase efficiency and improve a quality of management.

Consideration of the innovative process of informatization from the positions of different disciplines, as well as its synthesis with creative tools can lead to positive and original results. In the face of uncertainty, such a strategy can really be the foundation for building a flexible, efficient 
and competitive innovation organization, ready to successfully respond to the challenges of today's economy, thereby controlling the processes of creative destruction.

The issue of modeling the information architecture of an organization in the digital economy is quite closely related to the interaction between business and IT, that is, information management. However, the effective practical implementation of information management in organizations is possible only if there is a well-defined theoretical framework.

According to the conducted research, there is still no consensus among scientists about the essence of information management. Thus, the category "information management" by definition of the authors [1,2] is focused on the constant search for new, more effective ways of organizing information activities, on creating material and social prerequisites for effective access to information, on providing information-communication processes, to activate and develop existing information resources and forms of their rational use. It is also proved, that information management is not only an information management activity, but also an enterprise management based on this information [3, 4]. A broader definition of information management is formulated in [5], where information management is considered as a complex decision-making process to improve the efficiency of an enterprise on the basis of the system of information and communication means, optimization of sources of information and constant regulation of information flows. That is, recently the communication component of information technologies has received a proper assessment. The common displacement of the term "information technology" by the term "information and communication technology" illustrates this recognition process and indicates a fairly rapid development of different approaches to assessing the value of IT and IS for business, especially in the digital economy. As the need for computerization grows (to ensure accuracy, acceleration, synchronization of the use of one resource from separate territorial units), processes are being implemented that are functionally supported by the latest technologies. At the same time, there is a growing flow of information that is becoming increasingly difficult to manage. Such processes will only work if their interoperability exists, carried out by employees of an organization, the qualities of the employees themselves and the information technologies used $[5,6]$. Therefore, with the unconditional value of scientific development of the community of scientists, the need remains to substantiate theoretical and methodological recommendations and organizational provisions for determining how to functionally combine a business model of a business entity with the architecture of IS.

The purpose of the article is to identify methodological approaches to modeling the information architecture of an organization using information management tools. To achieve this goal, the following tasks are formulated:

1) Define the role of information management in modeling the information architecture of an organization;

2) Explore models of functional and strategic compatibility of business and technology, while building the organization's architecture;

3) Identify the advantages and disadvantages of different approaches to the modeling process;

4) Recommendations on theoretical and methodological substantiation and construction of the information architecture of an organization are offered.

\section{Materials and methods}

The theoretical justification is based on observations, groupings in identifying problems and trends in the use of an information technology in organizations that have been applied for a long time, summarizing the results and developing recommendations for building an information management grid, determining the "optimal" format that can be used to describe the IT-organization architecture, analysis of framework models, methods for describing the architecture of organizations. Methodological and general scientific principles of carrying out complex researches became the theoretical basis of the research. Based on the use of methods of generalization and analysis, conclusions and suggestions on approaches or framework models, as well as modern methods for describing the architecture of an enterprise are formed. 


\section{Results}

The strategic compatibility of a business strategy, organizational structure and business processes is known to ensure the viability of an organization. To support the integration of an information technology into the business strategy, it is advisable to use a strategic fit model by linking within and across the four domains. Translated from French, "domine" is an area, a unit of a structure. In computer science, a domain is theoretically a database (DB), a set of all valid atomic values, and in practice, it is metadata that abstractly describes a database (DB), including checks and constraints.

From the beginning of operation of an organization employees use information and IT in electronic or traditional, paper form. As the need for computerization grows (to ensure accuracy, acceleration, synchronization of the use of one resource from separate territorial units), processes, functionally supported by the latest technologies are being implemented. At the same time, there is a growing flow of information that is becoming increasingly difficult to manage. Such processes will work, only if their interoperability exists, carried out by the employees of the organization, the qualities of the employees themselves and the information technologies used (Fig. 1).

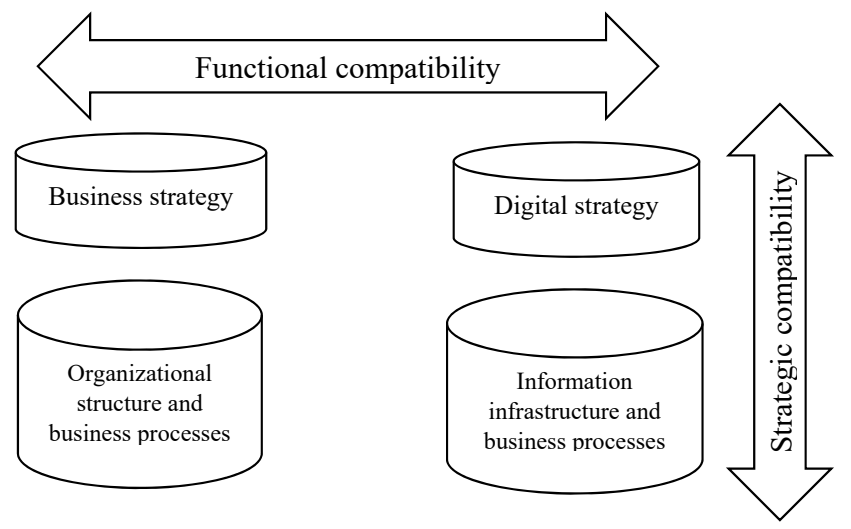

Fig. 1. Model of functional and strategic compatibility of business and technology

This strategic alignment model defines the relationship between business and technology fairly well, but is quite simplistic to use in practice. At the same time, one cannot but admit that it can serve as a basis for building more sophisticated tools.

In the future, an organization grows in terms of both the number of staff and the amount of functions performed, employees join the organizational units, there is a need to integrate IT processes into some IT infrastructure. If we summarize the critical remarks on this model and try to eliminate them, we can get an advanced scheme of managing the interaction between business and IT, that is information management.

The model in Fig. 1 becomes more sophisticated, if an organization identifies the operational level and the structural level, at which it is possible to track the process of creating IS for employee's operations, resulting in the management process, depicted in Fig. 2.

Fig. 2 depicts a classic way to use an information technology in an organization that has been used lately, when IT was viewed as an ancillary resource. With this approach, at the operations level, an information system is created for each specific user's operation on a case-by-case basis, at the structural level attempts are made to integrate IT into the IT infrastructure, and design the IS architecture under the organizational structure. At the strategic level, the IT strategy only has a "faint smell of business", not an understanding of the restructuring of business opportunities in the information technology. The numbers in Fig. 2 show the direction of movement as technology information systems start to be perceived as a restructuring resource, and the process of IS creation changes.

The development of the previous models becomes impossible without taking into account another factor - the information itself. As shown above, the introduction of any technology in an organization will lead to a fundamental change in its metamodel as it introduces a new syntax for 
communications, develops a new culture that ensures their effectiveness and is independent of organizational hierarchies and virtually uncontrolled.

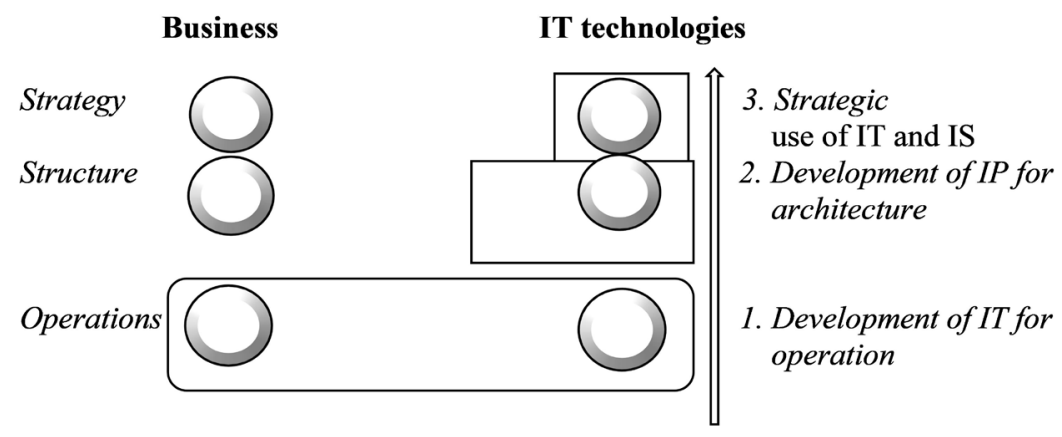

Fig. 2. Model of formation of management system through development of IS for business operations

Therefore, the researchers added an additional vertical to the above schemes and proposed some conceptual scheme, which can be called "information management grid" (Fig. 3).

With this model you can describe any organization at the operational, structural and strategic levels. The environment of an organization is given by "resources" and "environment". In this information management grid, there are three vertices and three horizontals.

The first vertical is the vertical of business. It defines the metamodel of an organization and reflects the direction of pragmatic application of information. The second vertical is information, which makes it possible to interpret information, communication and knowledge-sharing processes. It can be defined as a semantic component that reflects the dialogue between business and IT. The third vertical is technological, it shows the provision of a business technology. The three horizontals in the information management grid are three loops: a routine loop, a power loop, and a strategic organization loop.

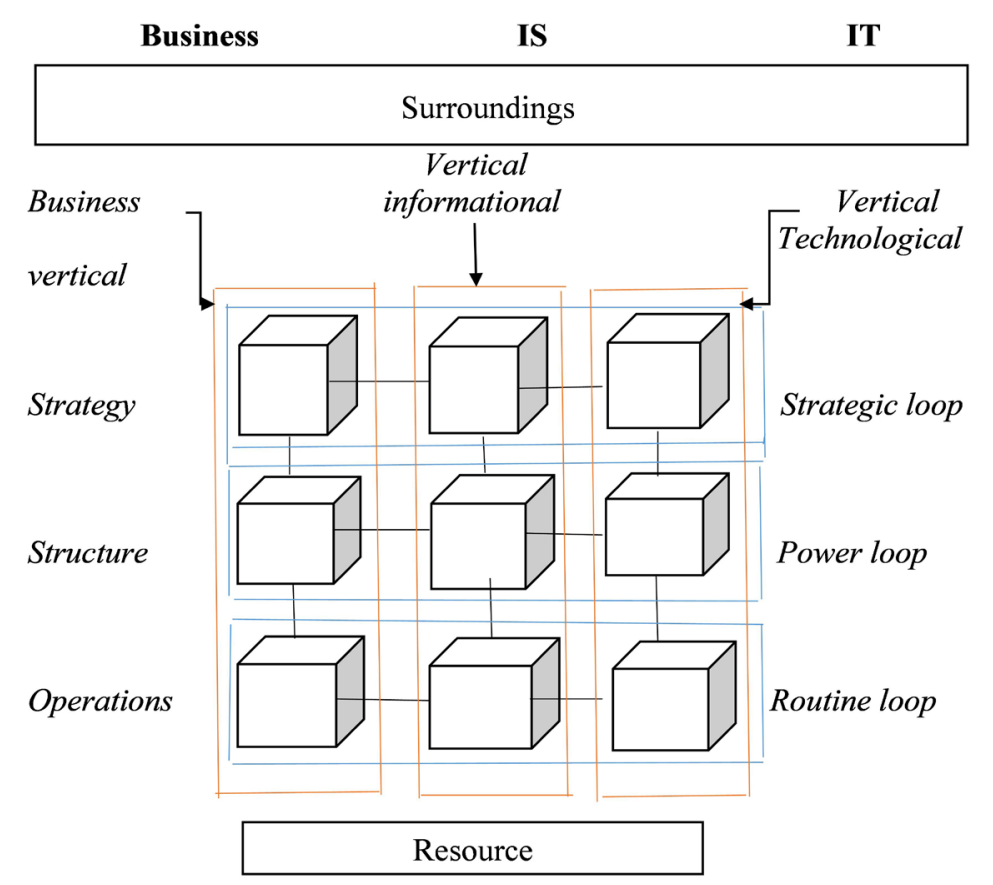

Fig. 3. Vertical and horizontal layers of the information management grid

The routine loop reflects the use of IT at the operational level by end users of the IS. At the intersection of the vertical "business" and routine loop work with customers, business functions 
and business processes are performed, in this stratification an organization "makes money". In order for any business act to be carried out, it is necessary to confirm it with the appropriate document (for example, to print an invoice, to receive a receipt, etc.), a certain number of hits to the database is required. This is the middle square of the lattice routine loop. And for the database to work, each access to it is served by a part of the technological vertical (in this case, by a computer). The power loop connects technology capabilities (part of the IT infrastructure), organization data (information and communications arrays) and software applications (described in the IS architecture), business units, organizational units (the business model of the organization). The strategic loop shows how the business strategy, the information and communication strategy and the technology strategy are linked in the organization. Through these three loops and three verticals, the organization's information technology transforms itself from an auxiliary resource into a strategic asset of the organization, in interaction with its other resources, which is of considerable value for designing the organization's architecture.

But with each passing year, the growth of information technology has led to an increase in the flow of information that is becoming increasingly difficult to manage. Organizations do not have time to evaluate how individual units will interact with each other, how individual technological solutions will be integrated. Due to these problems, according to estimates of various consulting companies, approximately $50 \%$ of IT projects in different industries do not finish as planned [7]. One way to solve them is to build an enterprise architecture that is a modern, innovative, and highly effective concept of strategic management that allows you to change your business faster and more purposefully to respond to environmental variations.

Organizations may use different formats to formally describe their IT architecture. It is important, that an organization chooses the format that provides an easy-to-understand way to guide the development of all aspects of IT in the organization. Therefore, it is natural to question the "optimal" format that can be used to describe IT architecture as a subset of enterprise architecture.

There are different approaches or framework models, techniques for describing enterprise architecture. These techniques define the main areas of architecture and the common principles for describing them in relation to each other, describing the rules (policies), standards, processes, models, used to define different elements of architecture at different levels of abstraction. The main techniques include the following: J. Zachman's model; TOGAF methodology; techniques, published by analytics companies, such as Gartner, Giga Group, META Group and others; POSIX 1003.23, which is based on Cap Gemini's developments for public use in 1996, etc.

For governmental organizations, there are special techniques that are developed with the support of the US Government FEAF (Federal Enterprise Architecture Framework) or used in the Department of Defense Architecture Framework (DDAF).

These techniques highlight the issues of identifying and documenting the basic elements of an organization's architecture and make it possible to resolve the problem of misunderstanding between the personnel involved, as they set out a common, equally understandable set of concepts and models to describe the elements of architecture for the benefit of different stakeholder categories. Different techniques tend to be targeted at different audiences and differ in the scope of the problem, focusing on specific areas, despite the fact that their concept is to gradually unify definitions, related to the organization's architecture. Some of the techniques focus on particular areas of the industry, the advantages of other approaches are more accurate documentation, and the following - they pay more attention to the process of transition from the existing to the future state of architecture.

Currently, industry standards are being applied to describe the architecture of an organization, adopted by such institutions as the International Organization for Standardization (ISO), The Open Group, the Institute of Electrical and Electronics Engineers (IEEE), and so on. But none of these standards is dominant and does not provide teams, responsible for the architecture development with all the tools, needed from a methodological point of view and from the point of view of the templates, used to describe the architecture. However, this accumulated arsenal of techniques and standards provides architects with a wide choice of architectural models, examples and experiences of different industries. At the same time, it is necessary to clearly understand, firstly, the 
difference between the methodology of describing the architecture and the architecture itself, and secondly, that the use of the same methodology can lead to the creation of completely different architectures of the enterprise due to differences in business and area activities of the organization, availability of a certain set of inherited systems, etc.

Let's look at some of the techniques and models that are most popular for use in information management. Thus, a significant contribution to the development of the concept of enterprise architecture was made by John A. Zachman, and his "model Zachman to describe the architecture of the enterprise" has undergone a certain evolution in its development and became the basis, on which many organizations created their own methods, description of the enterprise information infrastructure $[8,9]$. For convenience of description, J. Zachman proposed the so-called Zachman Framework for Enterprise Architecture, which has two main goals: on the one hand, to logically structure the organization's architecture into separate divisions to simplify their formation and perception, and, on the other, to provide consideration of holistic architecture from different angles or corresponding levels of abstraction.

The basic idea is to provide a consistent description of each aspect of the system in coordination with all others. For any complex system, the total number of terms, conditions, and rules generally exceeds the scope for the concurrent review. At the same time, separate from each other, the consideration of every aspect of the system often leads to suboptimal decisions, both in terms of performance and cost of implementation.

Actually, the model is presented in the form of a table - a matrix, the essence of which is to consider the activity of the company from different angles, since it is advisable to understand the vision of the system by each stakeholder and find a discrepancy between them. J. Zachman proposed a six by six matrix with five rows and six columns. Note, that there are five rows in the model, since the sixth row is no longer the level of description of the architecture, but the level of the working system or the enterprise as a whole. Each line represents an organization's vision from a specific perspective.

A generalization of J. Zachman's approach was proposed in the works of E.B. Zinder [9, 10]. The main idea of which is to provide opportunities to reflect the continuous development of an organization (and its information systems) as a continuous sequence of transformations. Instead of the traditional two-dimensional table, it was proposed to introduce a three-dimensional scheme, adding strategic time to the flat diagrams. On this axis there are segments of time of implementation of various projects and stages of development of information systems and the whole enterprise. Thus, a "three-dimensional" scheme of enterprise architecture or a model of "3D-enterprise" was created, which is built on three dimensions taking into account the time space. However, at the suggestion of the author of this work, the first two dimensions are similar to those, used by J. Zachman, but do not always coincide with the original completely in the content and interpretation. The third axis makes it possible to identify changes that have occurred and will occur with an organization, its existing information systems, and with various development and transformation projects.

It should be noted, that the proposed variant of the development of J. Zachman's initial approach may not be the only possible one. There are a number of model schemes that, to one degree or another, use this approach, despite the fact that the visual representation of the model as a whole may be quite different.

Since the concepts of "IS architecture" and "IT infrastructure" must be handled during each IS action, these concepts also have a life cycle. For example, the life cycle of an IS architecture consists of phases: initial documentation, use, design, change. For research purposes, it is important to note that there are many ISs within an organization, and each of them can be at its own life cycle stage. In order to illustrate this, we will take into account another tool of information management, which is based on the model of J. Zachman and proposed as a model of transformation of the system [10] (Fig. 4).

This model somewhat broadens the ideas, discussed above, and also emphasizes the relationship between the concepts of the Electronic Nervous System of the organization and the practical implementation of these ideas within modern approaches to the design of enterprise IT architec- 
ture: "The electronic nervous system is a set of electronic processes, through which organizations perceive the world and respond adequately to the changes taking place in it" [11].

In the figure, the set of ISs of an organization is seen as a set of layers of stages of the IS life cycle, each of which uses J. Sachman model to describe the ISs from the perspective of stakeholders.

Because the multidimensional cube itself is a reflection of the state of the organization at a particular point in time, changes in any IS during its lifecycle will be reflected as a new multidimensional cube.

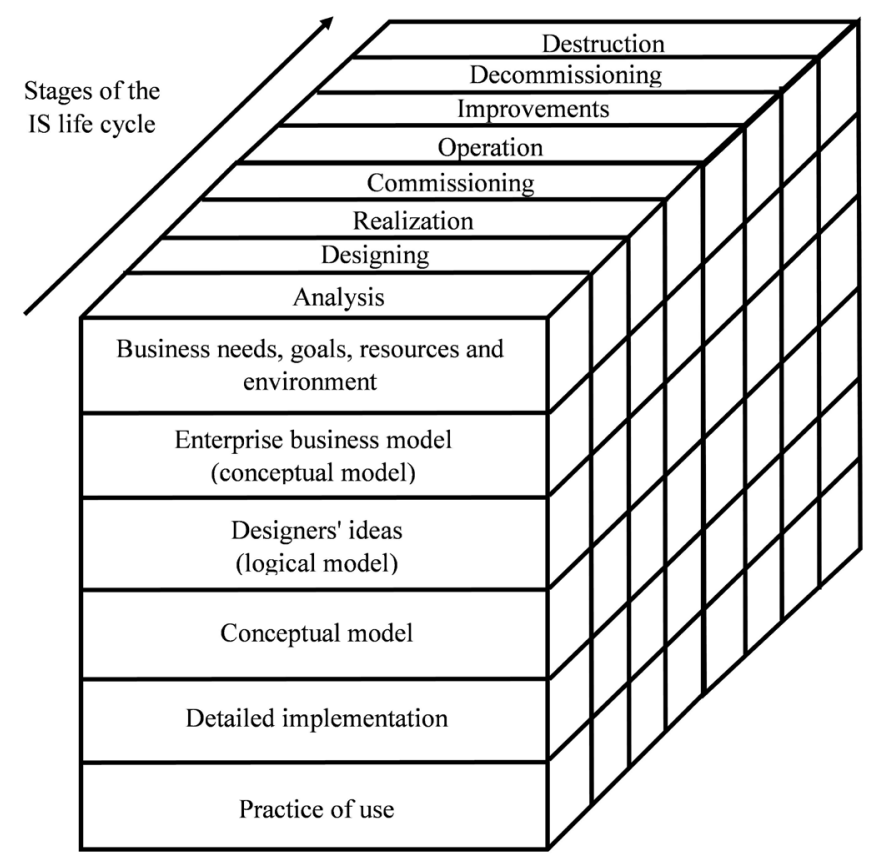

Fig. 4. Development of IS organizations in the life cycle stages (multidimensional cube of models by J. Zachman and E. Sinder [10]

The discretion of such actions is related to the degree of volatility of the organization itself, as the environment, in which the IS is managed, and to the plans of the organization's managers, who must coordinate their actions with their ideas about the value of each IS for the organization's business. Undoubtedly, the assessment of this value is related, first and foremost, to the positioning of each IS within the quadrants of J. Zachman's matrix, to the organization's strategy and current tasks.

That is, for all of the above models for the creation and use of information systems, the basis is J. Zachman's model, which is why we propose to use this model for the practical application in modeling the transformation of the business model of an organization and its management system in the digital economy.

\section{Conclusions}

The author defines approaches to planning of works on creation and use of information systems and their joining in organizations for the purposes of information management. The advantages and disadvantages of IS models in the form of an information management grid that can be applied to an individual employee, team, unit, business unit and organization as a whole are evaluated. Common methodologies of business process modeling are considered, as well as operating techniques and tools, through which ideas about the organization from the positions of business, IS design analysts and their developers are given. Their advantages and disadvantages in modeling are identified. Recommendations on theoretical and methodological substantiation and construction of the information architecture of an organization are offered. 
Taking into account the above knowledge and detailing the idea of enterprise architecture, we can say that its development is a process, based on a business strategy that coordinates the creation of the business architecture, information architecture, application systems architecture and technological architecture. Thus, enterprise architecture is a comprehensive description of key organizational strategies related to business, information, application systems and technologies, as well as their impact on the functions and business processes of an organization. The development of the organization's architecture is conducted in the appropriate context of the information management organization, existing at an enterprise.

\section{References}

[1] Matvienko, O. V., Tsivin, M. N. (2007). Information management: the basic synopsis of lectures in diagrams and tables. Kyiv: Word, 200.

[2] Kalinina, L. M. (2009). Genesis of information management as a field of scientific knowledge. Strategic priorities, 4 (13), 71-76.

[3] Kushnarenko, N. N. (2006). Documentation. Kyiv: Knowledge, 459.

[4] Melnyk, V. V. (2012). Formation of the concept of information management: essence, tasks, main directions of development. Humanitarian Bulletin of ZIA, 49, 122-134.

[5] Lukyanenko, D. I. (2013). Development of information management as a scientific category. Economics, organization and management of the enterprise. Scientific Bulletin of Poltava University of Economics and Trade, 1 (56), 186.

[6] Koryagin, N. D., Sukhorukov, A. I., Medvedev, A. V. (2015). Implementation of modern methodological approaches to management in management information systems. Moscow: RIO MGTU GA, 148.

[7] Methods for describing architectures. Zachman and Gartner models, META Group and TOGAF techniques. Available at: http://www.intuit.ru/studies/courses/995/152/lecture/4236?page=2

[8] Zachman, J. A. (1987). A framework for information systems architecture. IBM Systems Journal, 26 (3), 276-292. doi: http:// doi.org/10.1147/sj.263.0276

[9] Sowa, J. F., Zachman, J. A. (1992). Extending and formalizing the framework for information systems architecture. IBM Systems Journal, 31 (3), 590-616. doi: http://doi.org/10.1147/sj.313.0590

[10] Zinder, E. Z. (2013). Methods of architectural approach for ensuring the efficiency and effectiveness of e-government. Saint-Petersburg: ITU Research Institute, 138.

[11] Tukmacheva, Yu. A. (2017). Application of the stock model for solving the problems arising at the stage of it-project implementation. International scientific and technical journal. Theory. Practice. Innovation. 